\title{
Effects of Soil Compaction and Organic Carbon Content on Preferential Flow in Loamy Field Soils
}

\author{
Antonio Soares, Per Moldrup, Anders L. Vendelboe, Sheela Katuwal, Trine Norgaard, \\ Cristina Delerue-Matos, Markus Tuller, and Lis W. deJonge
}

\begin{abstract}
Preferential flow and transport through macropores affect plant water use efficiency and enhance leaching of agrochemicals and the trans- port of colloids, thereby increasing the risk for contamination of groundwa- ter resources. The effects of soil compaction, expressed in terms of bulk density (BD), and organic carbon (OC) content on preferential flow and transport were investigated using 150 undisturbed soil cores sampled from $15 \times 15-m$ grids on two field sites. Both fields had loamy textures, but one site had significantly higher OC content. Leaching experiments were conducted in each core by applying a constant irrigation rate of $10 \mathrm{~mm} \mathrm{~h}^{-1}$ with a pulse application of tritium tracer. Five percent tritium mass arrival times and apparent dispersivities were derived from each of the tracer breakthrough curves and correlated with texture, OC content, and BD to assess the spatial distribution of preferential flow and transport across the investigated fields.

Soils from both fields showed strong positive correlations between BD and preferential flow. Interestingly, the relationships between $\mathrm{BD}$ and tracer transport characteristics were markedly different for the two fields, although the relationship between BD and macroporosity was nearly identi$\mathrm{cal}$. The difference was likely caused by the higher contents of fines and $\mathrm{OC}$ at one of the fields leading to stronger aggregation, smaller matrix permeability, and a more pronounced pipe-like pore system with wellaligned macropores.
\end{abstract}

\section{Key Words}

Preferential flow, chemical transport, hydraulic conductivity, bulk density, organic carbon, macropores

Soils are highly heterogeneous and complex porous systems that, in many cases, contain large structural pores (e.g., desic- cation cracks or biological macropores). These pores commonly

promote preferential flow and transport of agrochemicals and colloid-sized particles and potentially lead to contamination of groundwater resources. There is no general agreement about the size range of macropores. Based on experimental evidence, Jarvis (2007) suggested considering pores larger than 0.3 to 0.5 $\mathrm{mm}$ as macropores that encompass shrinkage cracks, interaggregate voids, and earthworm and root channels. A recent comprehensive review by Beven and Germann (2013) clearly indicates that de- spite significant advancements in measurement technology and much focused research during the last decade, many aspects of preferential flow and transport are still poorly understood.

Preferential flow of water through soil macropores facilitates both the transport of solutes and colloid-sized particles with strongly sorbing compounds (Flury et al., 1994; Camobreco et al., 1996; Iversen et al., 2012). The higher level of continuity and lower tortuosity of structural pores (i.e., macropores) relative to textural pores yield elevated flow rates under certain boundary conditions, for example, if the infiltration capacity of the soil matrix is exceeded by the rainfall rate, resulting in a pronounced nonequilibrium state (Jarvis, 2007). This nonequilibrium behavior results from different gradients of water pressure or solute concentrations during vertical flow (Jarvis et al., 2007).

Angulo-Jaramillo et al. (1996) suggested that, for a given pore network topology, the mobile water content is dependent on both the dynamics of water movement and the connectivity of the pore network, indicative of the considerable effect macropores have on water transmission in soils with high water potentials (close to saturation). Seyfried and Rao (1987) documented significant preferential flow in an aggregated tropical soil at water potentials between 0 and $-1 \mathrm{~cm}$, and the different flow conditions between mobile and immobile water regions also promoted preferential flow, as shown in particular for undisturbed soils (Gaber et al., 1995; Langner et al., 1999). Vervoort et al. (1999) studied solute transport in two soils with highly contrasting structures and confirmed that larger dye dispersivity and weaker lateral mass exchange were associated with a well-developed structure. Koestel et al. (2012) reported a negative correlation between bulk density (BD) and the magnitude of preferential flow and transport based on analysis of 733 breakthrough curves (BTC). More recently, Koestel et al. (2013) reported that the extent of preferential transport was positively correlated to BD and the degree of water saturation.

A description of soil macropore attributes and their influence on water and chemical movement through the soil profile may be obtained by means of tracer breakthrough experiments (Biggar and Nielsen, 1962; Anderson and Bouma, 1977; Jarvis et al., 2007), which enable the determination of the apparent dispersivity and tracer-specific mass arrival time. Koestel et al. (2011) analyzed and related the shape of solute BTC to model-independent indicators, identifying the arrival of $5 \%$ of the tracer mass as the most reliable parameter for the analysis of preferential flow and transport. Biggar and Nielsen (1962) concluded that the shape of a BTC depends on the microscopic flow velocity distribution and on the amount of water that is readily displaced. They showed 
that increasing aggregate sizes promoted an early tracer breakthrough, indicating preferential flow. Anderson and Bouma (1977) showed that differences in dispersion are clearly related to differences in soil structure. Anamosa et al. (1990) showed that approximately $50 \%$ of the water within the soil porous system is immobile, thereby emphasizing the considerable effect of soil structural properties on rapid transport of solutes. Furthermore, the formation and stabilization of soil structure are known to be affected by basic soil characteristics, such as texture and organic matter (OM) content (Oades, 1993; Horn et al., 1994).

Motivated by the Danish Pesticide Leaching Assessment Program (PLAP), the main focus of this study was to investigate the variation of preferential flow across two agricultural fields, one in Faardrup with experimental data collected in the course of this project and the second in Silstrup with measurements previously presented in Norgaard et al. (2012). Within this context, the specific objectives were (i) to measure basic and functional parameters such as organic carbon (OC), texture, BD, volumetric content of pores more than $150 \mu \mathrm{m}\left(\varepsilon_{-20}\right)$, and saturated hydraulic conductivity $\left(K_{\mathrm{SAT}}\right)$ and (ii) to derive structural characteristics from tracer BTC (5\% tritium mass arrival time, mass recovery, and apparent dispersivity) to generate maps for the two field sites depicting the spatial distribution of preferential flow and transport parameters.

\section{MATERIALS ANDMETHODS}

\section{Field Sites}

As part of the Danish PLAP, five sites representing major Danish soil types and climatic conditions were initially established in 1998 to monitor pesticide leaching from agricultural production systems (Kjaer et al., 2011). The two best characterized and most representative sites, one in northern Denmark in Silstrup $\left(56^{\circ} 55^{\prime}\right.$ $\left.56.16^{\prime \prime} \mathrm{N}, 8^{\circ} 38^{\prime} 43.91 " \mathrm{E}\right)$ and the other in eastern Denmark in Faardrup $\left(55^{\circ} 19^{\prime} 1.09^{\prime \prime} \mathrm{N}, 11^{\circ} 20^{\prime} 34.12^{\prime \prime E}\right)$ (Fig. 1), were designated for this study. The field in Faardrup (Fig. 1B) extends over an area of 2.3 ha $(150 \times 160 \mathrm{~m})$, and the site in Silstrup covers 1.69 ha $(185 \times 90 \mathrm{~m})$ (Fig. 1C). Average annual precipitation during the period 1961 to 1990 for the sites at Faardrup and at Silstrup were $558 \mathrm{~mm}$ and $866 \mathrm{~mm}$, respectively (Lindhardt et al., 2001).

The Faardrup field has been cultivated since 1940. The last seed bed preparation for spring barley occurred in April 2010, with the barley harvested in August 2010. At the time of sampling, red fescue (Festuca rubra L.) was established on both sites with notillage applied for at least 1 year. Down to a depth of $1.5 \mathrm{~m}$, a significant number of vertical clay (CL)-coated fractures (desiccation cracks) and numerous wormholes and root channels that decreased in number with depth were present (Lindhardt et al., 2001).

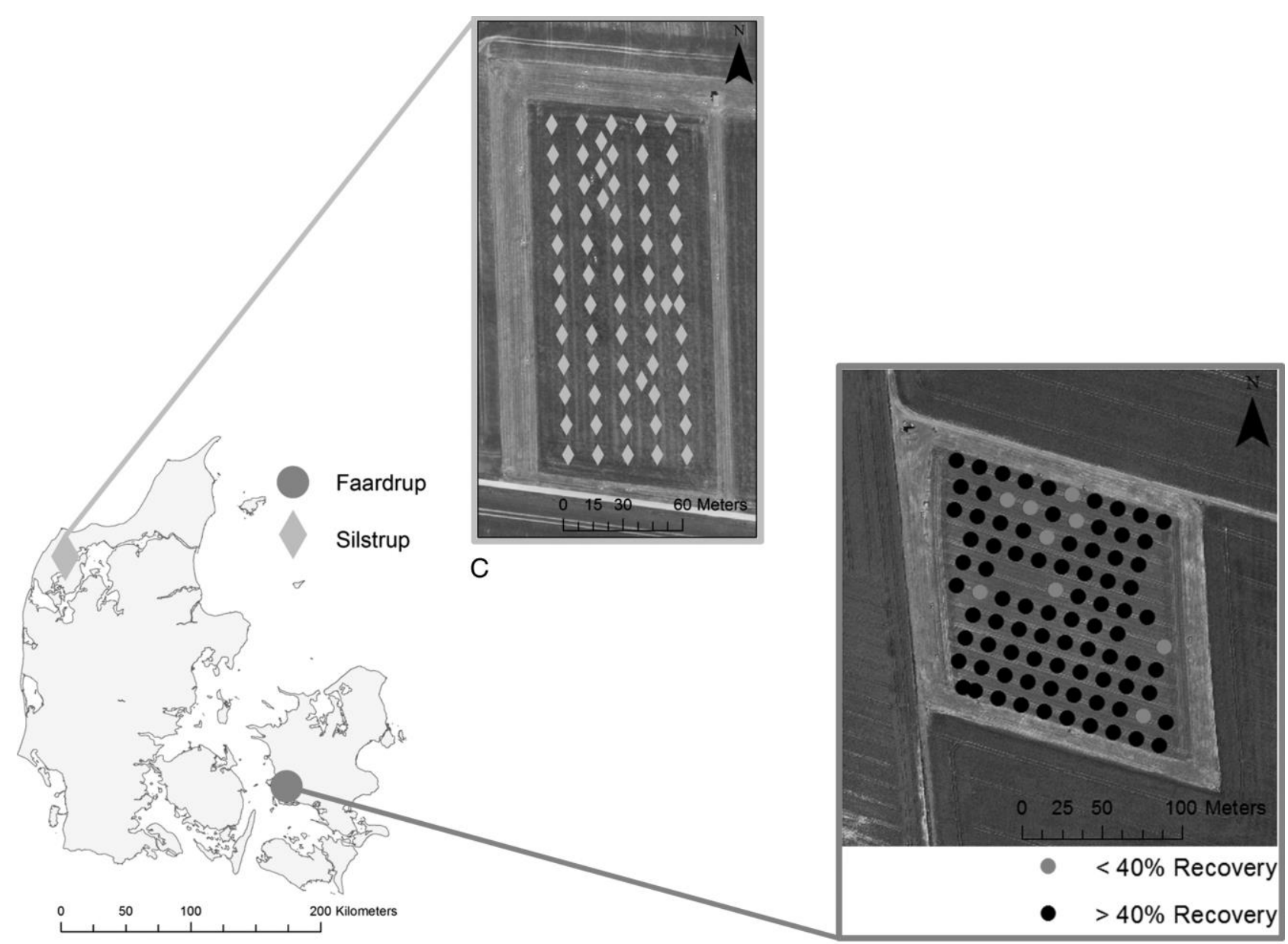

A

$\mathrm{B}$

FIG. 1. Locations of the PLAP field sites (A). Sampling schemes at Faardrup (B) and Silstrup (C). 
The Silstrup field has been farmed since 1942. Before sampling, the field was sown with spring barley in April 2009 and harvested in September 2009 (Norgaard et al., 2012). The topsoil is composed of noncalcareous material and is heavily fractured and bioturbated by vertical desiccation fractures and biopores, with numerous burrows and roots.

For more detailed information about PLAP, the field sites, and the site-specific management practices and hydrogeological properties, readers are referred to Lindhardt et al. (2001) and Kjaer et al. $(2007,2011)$

\section{Soil Sampling}

A total of 89 undisturbed cylindrical core samples were collected from the topsoil $(0-0.20 \mathrm{~m})$ at the Faardrup site in April 2011 on a grid of $15 \times 15 \mathrm{~m}$. To avoid systematic sampling errors, for example, sampling in tractor tracks, sampling points were either located directly on the grid points or shifted $1 \mathrm{~m}$ in random directions. The cores were extracted by slowly pushing aluminum sampling cylinders $(20 \mathrm{~cm}$ in diameter and $20 \mathrm{~cm}$ long) into the soil with a tractor-mounted hydraulic press while simultaneously excavating the surrounding material. After extraction, the ends were carefully trimmed and covered with plastic lids. After transport to the laboratory, the cores were stored in an environmentally controlled room at $2^{\circ} \mathrm{C}$ before analysis. Bulk soil samples were collected in close vicinity to the grid points at the same depth and used for determination of soil texture and OC. The same sampling strategy was applied at the Silstrup site where 65 locations were sampled (Norgaard et al., 2012).

\section{Physicochemical Soil Properties}

Soil texture was determined using a combination of sieving and hydrometer methods (Gee and Or, 2002). Dry BD was calculated from the oven-dry mass $\left(105^{\circ} \mathrm{C}\right)$, and the volume of the core samples was determined after the breakthrough experiments. Porosity was estimated from measured BD and an assumed particle density of $2.65 \mathrm{~g} \mathrm{~cm}^{-3}$. Organic carbon content was measured on

ball-milled samples with a FLASH 2000 NC organic elemental analyzer (Thermo Fisher Scientific Inc., Waltham, MA); pH was measured in a 1:4 soil/water extract (volumetric basis) and electrical conductivity (EC) on a 1:9 soil/water extract. Contour maps for the main soil properties were generated with ordinary kriging in ArcMap 10.1 (Esri, Redlands, CA).

\section{Tritium Breakthrough Experiments}

Before the tritium breakthrough experiments, all soil cores were saturated on ceramic plates with an artificial soil-water solution $\left(0.652 \mathrm{mmol} \mathrm{L}^{-1} \mathrm{NaCl}, 0.025 \mathrm{mmol} \mathrm{L}^{-1} \mathrm{KCl}, 1.842 \mathrm{mmol} \mathrm{L}^{-1}\right.$ $\mathrm{CaCl}_{2}, 0.255 \mathrm{mmol} \mathrm{L}^{-1} \mathrm{MgCl}_{2} ; \mathrm{pH}$ 6.38; EC, $0.6 \mathrm{mS} \mathrm{cm}^{-1}$ ) for 3 days and then drained at a matric potential of $-10 \mathrm{hPa}$ applied to the bottom of the cores for another 3 days. In this state, the matric potential in the $20-\mathrm{cm}$ tall soil cores varied from $-10 \mathrm{hPa}$ at the bottom to $-30 \mathrm{hPa}$ at the top. To estimate the ability of the soils to conduct air by means of convection, the macroporosity, $\varepsilon-20$ (volumetric content of pores $>150 \mu \mathrm{m}$ in samples drained at a matric potential of $-20 \mathrm{~cm} \mathrm{H}_{2} \mathrm{O}$ ), was determined as:

$$
\varepsilon_{-20}=\text { Porosity-Volumetric Water } \text { Content }_{(-20)}
$$

Breakthrough experiments were conducted with a drip intiltrometer on drained soil cores with a constant influx of artificial rainwater (0.012 $\mathrm{mmol} \mathrm{L}^{-1} \mathrm{CaCl}_{2}, 0.015 \mathrm{mmol} \mathrm{L}^{-1} \mathrm{MgCl}_{2}, 0.121 \mathrm{mmol} \mathrm{L}^{-1}$ $\mathrm{NaCl}$; EC, $0.025 \mathrm{mS} \mathrm{cm}^{-1}$; $\mathrm{pH} 5.76-7.26$ ) at a rate of $10 \mathrm{~mm} \mathrm{~h}^{-1}$ at the top of the cores and free drainage from the bottom. The setup for the leaching experiments has been previously described in Norgaard et al. (2012). After attainment of steady-state flow conditions, tritium tracer was applied as a pulse input at $10 \mathrm{~mm} \mathrm{~h}^{-1}$, replacing rainwater for $10 \mathrm{~min}$. The effluent was collected at 10 to 30-min intervals for $6.5 \mathrm{~h}$ for samples from Silstrup and for $10 \mathrm{~h}$ for samples from Faardrup. The longer duration of the experiment for the Faardrup samples was to achieve higher tritium tracer recovery in the effluent. The tracer concentration in the outflow was analyzed with a TRI-CARB 2250CA liquid scintillating analyzer (PerkinElmer Inc., Waltham, MA), and the tracer mass recovery was analyzed at various time intervals to develop the BTC. After completion of the breakthrough experiments, samples from Faardrup were slowly resaturated from the bottom for 1 day and $K_{\text {SAT }}$ was measured with the constant head method as discussed in Klute and Dirksen (1986). Darcy's law was applied to calculate $K_{\mathrm{SAT}}$ :

$$
K_{S A T}=\frac{V \cdot L}{A \cdot t \cdot \Delta H}
$$

where $V$ is the volume of discharged water $\left(\mathrm{cm}^{3}\right), L$ is the length of the core $(\mathrm{cm}), A$ is the cross-sectional area of the core $\left(\mathrm{cm}^{2}\right), t$ is the discharge time (s), and $\Delta H$ is the hydraulic head difference across a distance $L(\mathrm{~cm})$.

\section{Analysis of Tritium BTC}

The measured tritium BTC were analyzed for apparent tritium dispersivity, 5\% tritium mass arrival time, and total tritium mass recovery throughout the breakthrough experiment. The apparent tritium dispersivities were calculated from the temporal moments of the tritium BTC. The BTC were first approximated with a double log-normal distribution function as (Jury and Roth, 1990):

$$
f(t)=w_{1} g_{1}(t)+w_{2} g_{2}(t)
$$

where $g_{1}(t)$ and $g_{2}(t)$ are log-normal functions with weighing factors $w_{1}$ and $w_{2}$ that sum up to unity $\left(w_{1}+w_{2}=1\right)$. The log-normal probability density functions are given as:

$$
g(t)=\frac{1}{\sqrt{2 \pi} \sigma t} \exp \left(\frac{(\ln t-\mu)^{2}}{2 \sigma^{2}}\right)
$$

where $\mu$ is the log-normalized mean, and $\sigma$ is the log-normalized standard deviation of $g(t)$.

The parameterization of the double log-normal distribution functions was conducted with R software (version 2.14.1) closely following the procedure provided in Koestel et al. (2013). In brief, the measured BTC data points $(f(t))$ were first discretized to a temporal resolution of $2 \mathrm{~min}$ by linear interpolation. Then the double log-normal distribution function given in Eq.(3) was fitted to the discretized BTC data points. For the optimization of the fitting parameters, an adaptive nonlinear least-squares algorithm (NL2SOL in the "port" library in R; Dennis et al., 1981) was used. Then the zeroth and first moments were calculated for the time equal to double the pore volume:

$$
m_{p}=\int{ }_{0}^{t} t^{p} f(t) d t
$$

where $m$ denotes the moment of order $p$ and $p=0$ and 1 for zeroth and first-order moment, respectively. For calculating the moments with Eq.(5), the fitted data points were again discretized to a temporal resolution of $0.01 \mathrm{~h}$, and the integrals were calculated 
TABLE 1. Measured Physicochemical Properties for the Faardrup and Silstrup Soils

\begin{tabular}{|c|c|c|c|c|c|c|c|c|c|c|}
\hline & & $\begin{array}{c}\mathrm{CL} \\
(<2 \mu \mathrm{m})\end{array}$ & $\begin{array}{c}\text { Silt } \\
(2-50 \mu \mathrm{m})\end{array}$ & $\begin{array}{c}\text { Fine Sand } \\
(50-125 \mu \mathrm{m})\end{array}$ & $\begin{array}{c}\text { Medium Sand } \\
(125-500 \mu \mathrm{m})\end{array}$ & $\begin{array}{c}\text { Coarse Sand } \\
(500-2,000 \mu \mathrm{m})\end{array}$ & $\mathrm{OC}$ & $\mathrm{BD}$ & \multirow[t]{2}{*}{$\mathrm{pH}$} & \multirow{2}{*}{$\frac{\mathrm{EC}}{\mathrm{mS}} \mathrm{cm}^{-1}$} \\
\hline & & $\mathrm{kg} \mathrm{kg}^{-1}$ & $\mathrm{~kg} \mathrm{~kg}^{-1}$ & $\mathrm{~kg} \mathrm{~kg}^{-1}$ & $\mathrm{~kg} \mathrm{~kg}^{-1}$ & $\mathrm{~kg} \mathrm{~kg}^{-1}$ & $\mathrm{~kg} \mathrm{~kg}^{-1}$ & $\mathrm{gcm}^{-3}$ & & \\
\hline \multirow[t]{3}{*}{ FAARDRUP } & Avg & 0.12 & 0.24 & 0.24 & 0.31 & 0.07 & 0.013 & 1.54 & 6.60 & 0.75 \\
\hline & Min & 0.10 & 0.16 & 0.20 & 0.25 & 0.04 & 0.011 & 1.36 & 5.84 & 0.41 \\
\hline & Max & 0.19 & 0.31 & 0.30 & 0.36 & 0.09 & 0.017 & 1.75 & 7.68 & 1.14 \\
\hline \multirow[t]{3}{*}{ SILSTRUP } & Avg & 0.16 & 0.30 & 0.20 & 0.09 & 0.22 & 0.020 & 1.50 & 6.75 & 0.47 \\
\hline & Min & 0.14 & 0.23 & 0.17 & 0.07 & 0.19 & 0.017 & 1.39 & 6.39 & 0.40 \\
\hline & $\operatorname{Max}$ & 0.19 & 0.33 & 0.23 & 0.10 & 0.32 & 0.022 & 1.63 & 7.49 & 0.71 \\
\hline
\end{tabular}

applying the trapezoidal rule. The apparent dispersivity $(\lambda, \mathrm{cm})$ was calculated as (Jury and Roth, 1990; Stagnitti et al., 2000):

$$
\lambda=\frac{\mu_{2} L}{2\left(\mu_{1}^{\prime}\right)^{2}}
$$

where $\mu_{2}$ is the normalized second central moment that quantifies the variance of BTC, calculated as:

$$
\mu^{\prime} \quad \mu_{2}=\frac{1}{m_{0}} \int{ }_{0}^{t}\left(t-\mu_{1}^{\prime}\right)^{2} f(t) d t
$$

${ }_{l}$ is the normalized first moment, ratio of $m_{1}$ and $m_{0}$, and represents the mean breakthrough time of the tracer, and $L$ is the length of soil core $(\mathrm{cm})$.

The $5 \%$ tritium mass arrival time is defined as the time when $5 \%$ of the applied tritium has been recovered in the effluent and was calculated from the mass-accumulated tritium curves.

\section{RESULTS ANDDISCUSSION}

\section{Soil Physical and Chemical Properties}

The measured physicochemical soil properties for both field sites are listed in Table 1 . The texture of the Silstrup soil was classified as sandy loam to loam based on the USDA classification scheme and the texture of the Faardrup soil as sandy loam (Soil Survey Staff, 1999). The CL, silt, and OM contents were significantly higher in the Silstrupsoil.

Dexter et al. (2008) presented an index $n$ to classify soils on the basis of the amount of CL associated with OC. The index $n=\mathrm{CL} / \mathrm{OC}$ is effective in grouping soils on the basis of the amount of complexed CL that controls soil physical processes such as water retention, water repellence, and soil self-organization (Dexter, 1988; de Jonge et al., 2009). A threshold value of $n=10$ was proposed to mark CL saturation for both low OC arable and high OC pasture soils (Dexter et al., 2008; de Jonge et al., 2009). For $n<10$, all CL particles are complexed by OC and there is an excess amount of OC. For $n>10$, there is an amount of noncomplexed CL that may contribute to the pool of readily dispersible CL and act as a cementing agent leading to nonsatisfactory tilth conditions (de Jonge et al., 2009). Schjønning et al. (2012) expanded the findings of Dexter et al. (2008) and related the fines fraction $(\mathrm{CL}+$ silt $<20 \mu \mathrm{m})$ to $\mathrm{OC}$ and defined a threshold of $n^{*}=20$ separating dispersible from nondispersible CL.

Figure 2 depicts the CL as well as the fines fraction plotted against $\mathrm{OC}$ for the Faardrup and Silstrup soils. The solid line represents a CL-to-OC ratio of $n=10$. In general, the content of fines ranged from 0.23 to $0.38 \mathrm{~kg} \mathrm{~kg}^{-1}$ in the Faardrup samples (average of $0.28 \mathrm{~kg} \mathrm{~kg}^{-1}$ ) and, similar to the CL fraction, the fines fraction seventy-11ve percent of the Faardrup samples felf within $\eta_{*}$ values $^{-1}$ ).

of 20 and 27 , mostly concentrated around $n^{*}=20$, whereas the Silstrup samples were within $n^{*}$ values of 15 and 20 .

\section{Tritjum, Air and WaterTransport}

$77 \mathrm{~min}$ (average of $22 \mathrm{~min}$ ). At steady-state outflow, tritium was applied as a pulse for a period of $10 \mathrm{~min}$ As BD was identified as the main driver for several soil func-

tional properties at Silstrup (Norgaard et al., 2012), Fig. 3 shows measured BTC for Faardrup grouped for different BD ranges in ascending order. Breakthrough curves with less than $40 \%$ tritium mass recovery are depicted in black. Norgaard et al. (2012) showed that BD is an important soil parameter that reflects development and evolution of structural pores and associated preferential flow and transport processes. The shapes of the BTC in Fig. 3 varied from relatively symmetrical with slight left skews to very pronounced left skews with large and early tritium arrival peaks. For lower BD (groups 1 to 3 with BD less than $1.53 \mathrm{~g} \mathrm{~cm}^{-3}$ ), the measured BTC were generally symmetrical, with tracer peak arrival times beyond 3 to $4 \mathrm{~h}$, indicating relatively low water flow rates within the small and rather tortuous intra-aggregatepores.

As BD increases (groups 4 to 6 with $\mathrm{BD}$ more than $1.53 \mathrm{~g} \mathrm{~cm}^{-3}$ ), BTC were gradually more skewed to the left, with

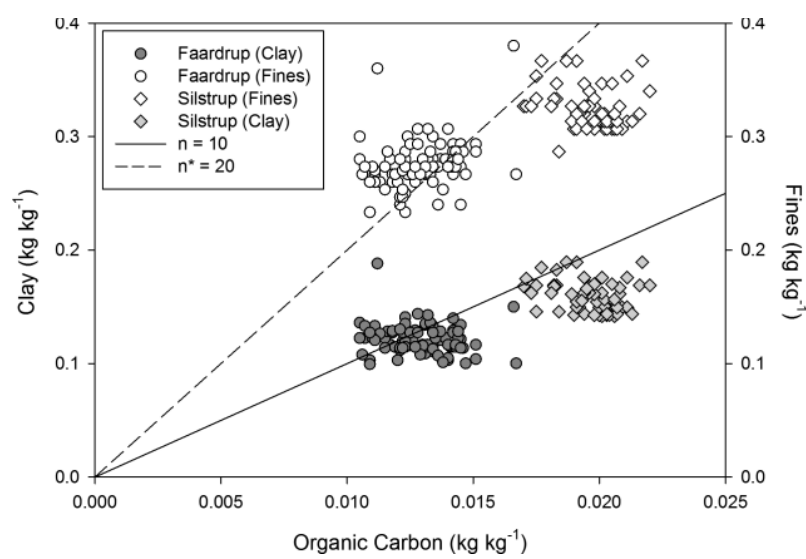

FIG. 2. Clay contents and fines fractions $(\mathrm{CL}+$ silt $<20 \mu \mathrm{m})$ plotted against $\mathrm{OC}$ contents for the Faardrup and Silstrup soils. The ratios of $\mathrm{CL}$ and OC and fines and OC are depicted for $n=10$ and $n^{*}=20$, respectively. 

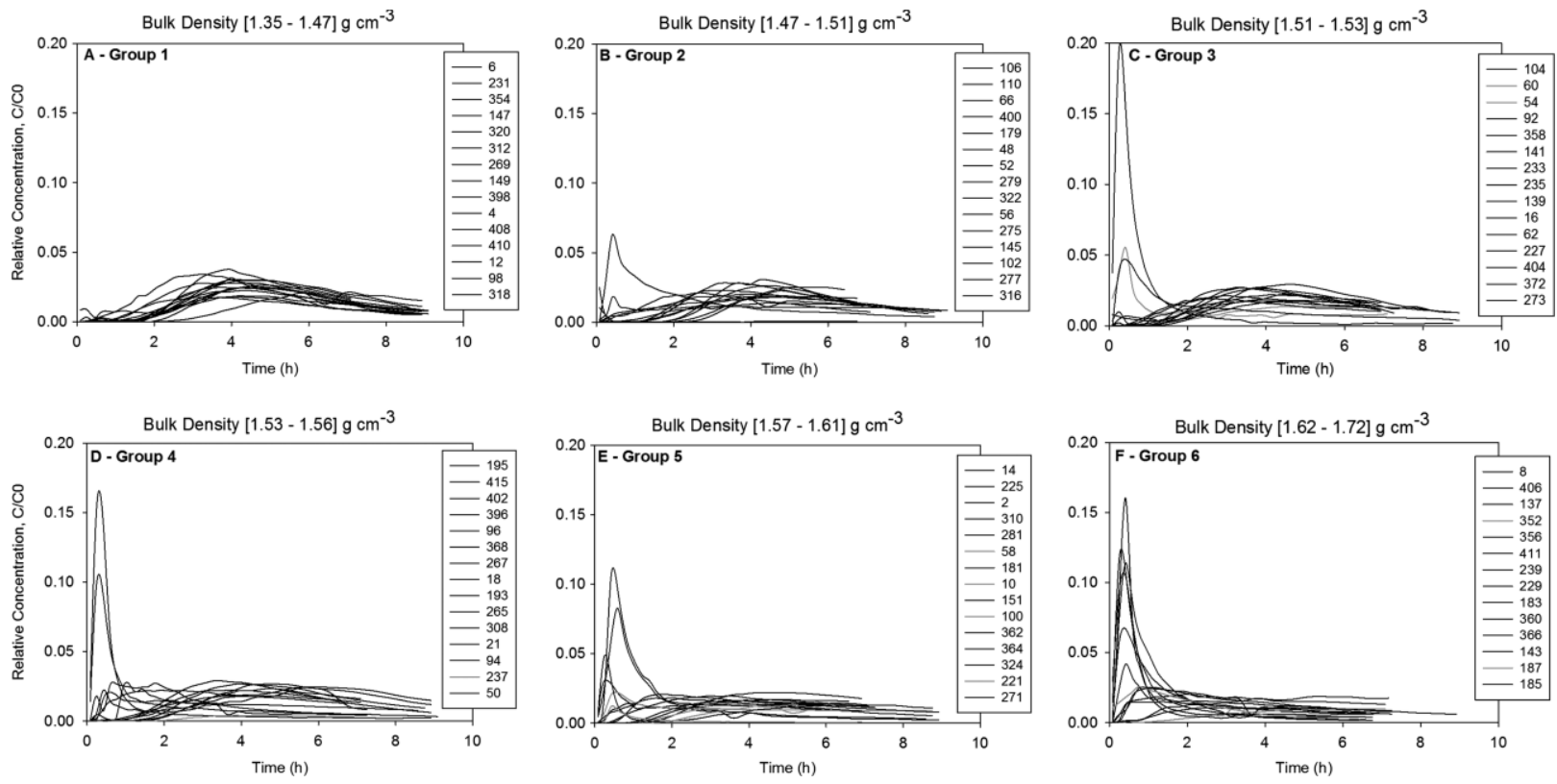

FIG. 3. Tritium BTC grouped according to ascending BD for the Faardrup samples. Black curves represent samples with less than $40 \%$ tritium recovery.

early and high peak concentrations followed by a long tailing section indicating diffusion and retardation of tritium in the soil matrix. For $\mathrm{BD}$ values of 1.53 and $1.56 \mathrm{~g} \mathrm{~cm}^{-3}$, a majority of the samples exhibited a symmetrical shape representative of matrix-dominated transport. The early breakthrough times and high peak concentrations are indicative of rapid preferential flow and transport of water and solutes through continuous macropores (Seyfried and Rao, 1987; Gaber et al., 1995; Langner et al., 1999; Kjaergaard et al., 2004; Norgaard et al., 2012). The vast majority of BTC depicted in Fig. 3 peaked about $4 \mathrm{~h}$ after application of the tritium pulse, which is common for soils with CL contents of about 12\% (Kjaergaard et al., 2004). Kjaergaard et al. (2004) concluded that pore size distribution and the continuity of the water-filled pore system are key factors controlling the transport behavior of tritium and therefore preferential flow. Ghafoor et al. (2013) suggested that the matrix hydraulic conductivity significantly influences the flow regime and consequently the shape of the BTC. In our study, the irrigation rate was the same for all
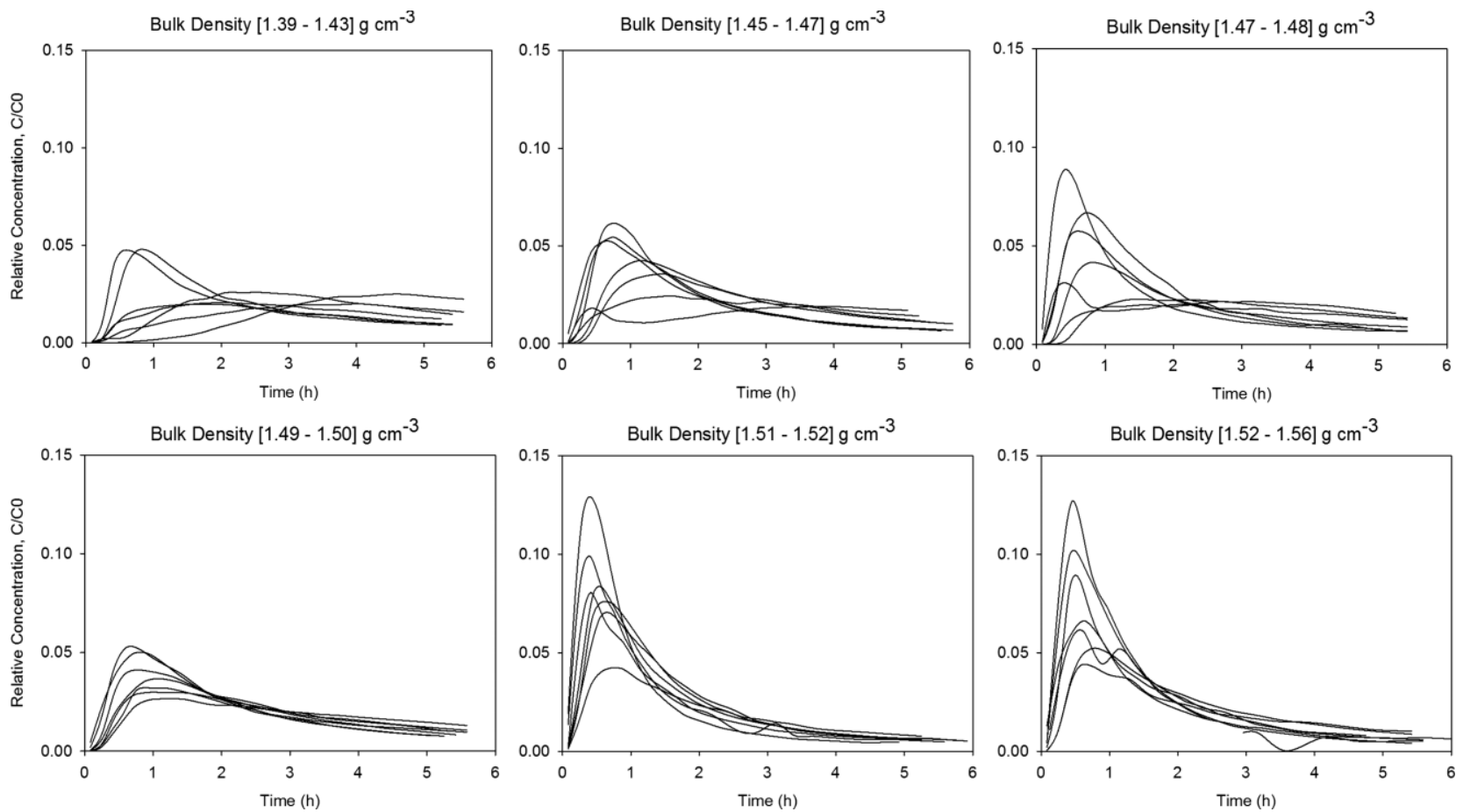

FIG. 4. Tritium BTC grouped according to ascending BD for the Silstrup samples. 

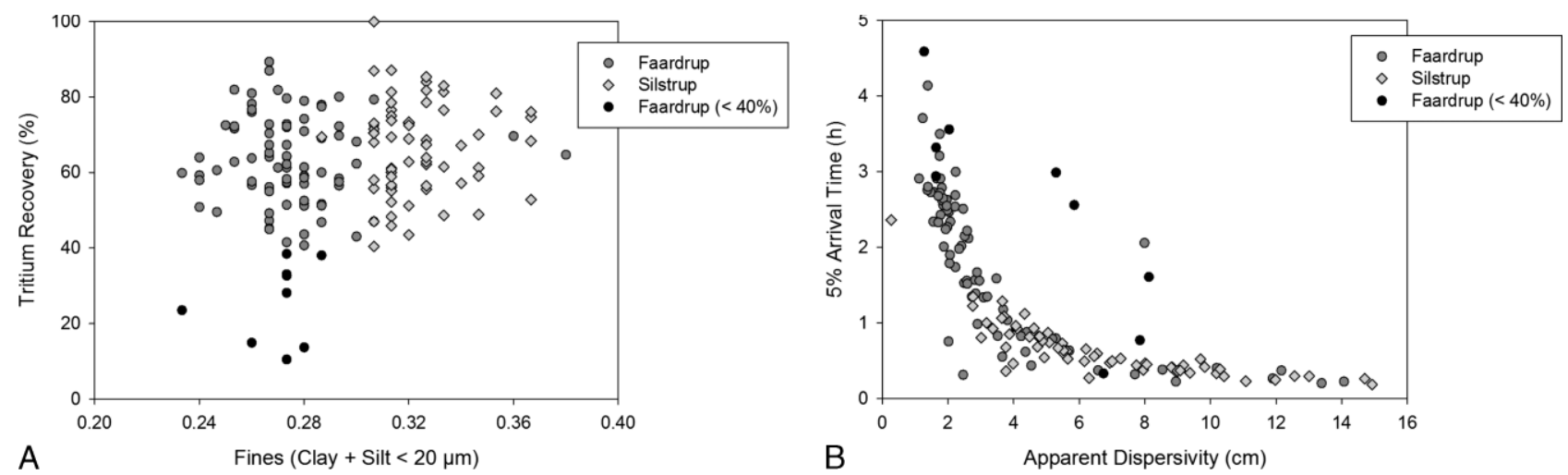

FIG. 5. Tritium mass recovery as a function of fines content (A) and $5 \%$ mass arrival time as a function of apparent dispersivity (B) for the Faardrup and Silstrup samples.

cores, but cores with low hydraulic conductivity may exhibit higher saturation with all macropores conducting liquid whereas, in cores with higher hydraulic conductivities, not all macropores are likely to be activated.

Figure 4 shows the BTC for Silstrup grouped according to BD (Norgaard et al., 2012). Norgaard et al. (2012) found that these BTC peaked after a very short time, generally less than $1 \mathrm{~h}$, representing a soil structure with a few well-aligned and wellconnected macropores. Thus, the more clayey texture (average CL content of $16.4 \mathrm{~kg} \mathrm{~kg}^{-1}$ ) in Silstrup exhibited a lower degree of matrix conductivity and a higher degree of preferential flow resulting in rapid transport of tritium (Norgaard et al., 2012), according to previous studies (Lin et al., 1999; Jarvis et al., 2013).
The different transport behavior observed at the two sites most likely results from differences in soil texture, as also suggested by Ghafoor et al. (2013). Norgaard et al. (2012) also suggested that a more structured soil (e.g., Silstrup) with higher CL content promotes the formation of a network of continuous macropores, which facilitates preferential flow of water and air.

The content of fines did not affect total tritium mass recovery (Fig. 5A) for either of the two fields, despite the larger content of fines in the Silstrup. The relationship between apparent dispersivities and 5\% tritium mass arrival times depicted in Fig. 5B revealed significantly higher $5 \%$ tritium mass arrival times for the Faardrup samples (average of $1.8 \mathrm{~h}$ ) than for the Silstrup samples (average of $0.6 \mathrm{~h}$ ). Generally, for both fields, soils with a shorter

TABLE 2. Pearson's Correlation Coefficient, $r$, for Faardrup ( 80 Samples, Red Color, $>40 \%$ Recovery), and Silstrup (65 Samples, Blue Color)

\begin{tabular}{|c|c|c|c|c|c|c|c|c|c|c|c|}
\hline & $\begin{array}{c}\mathrm{OC}, \\
\mathrm{kg} \mathrm{kg}^{-1}\end{array}$ & $\begin{array}{c}\mathrm{CL} \\
\mathrm{kgkg}^{-1}\end{array}$ & $\begin{array}{c}\text { Silt, } \\
\mathrm{kg} \mathrm{kg}^{-1}\end{array}$ & $\begin{array}{c}\text { Sand, } \\
\mathrm{kgkg}^{-1}\end{array}$ & $\begin{array}{c}\mathrm{BD}, \\
\mathrm{g} \mathrm{cm}^{-3}\end{array}$ & Dexter, $n$ & $n^{*}$ & $\begin{array}{c}5 \% \text { Arrival } \\
\text { Time, h }\end{array}$ & $\begin{array}{c}\text { App. Disp., } \\
\mathrm{cm}\end{array}$ & $\begin{array}{c}\log K_{\mathrm{SAT}} \\
\mathrm{md}^{-1}\end{array}$ & $\begin{array}{c}\varepsilon_{-20}, \\
\mathrm{~cm}^{3} \mathrm{~cm}^{-3} \\
\end{array}$ \\
\hline \multirow{2}{*}{$\begin{array}{l}\mathrm{OC}, \\
\mathrm{kg} \mathrm{kg}^{-1}\end{array}$} & 1.00 & -0.164 & $0.262 *$ & -0.188 & $-0.201 *$ & $-0.736 * * *$ & $-0.717 * * *$ & -0.000556 & -0.0630 & 0.205 & -0.0613 \\
\hline & & $0.245^{*}$ & 0.194 & -0.0921 & $-0.458 * * *$ & $-0.714 * * *$ & $-0.842 * * *$ & 0.203 & -0.203 & & $0.344 * *$ \\
\hline \multirow{2}{*}{$\begin{array}{l}\mathrm{CL}, \\
\quad \mathrm{kg} \mathrm{kg}^{-1}\end{array}$} & & 1.00 & $0.266^{*}$ & $-0.710 * * *$ & 0.176 & 0.776 *** & $0.618 * * *$ & -0.0781 & 0.158 & 0.0217 & 0.117 \\
\hline & & & -0.00657 & $-0.597 * * *$ & 0.135 & $0.851^{* * *}$ & -0.111 & -0.145 & -0.00241 & & $-0.261^{*}$ \\
\hline \multirow{2}{*}{$\begin{array}{l}\text { Silt, } \\
\qquad \mathrm{kg} \mathrm{kg}^{-1}\end{array}$} & & & 1.00 & $-0.862 * * *$ & -0.0583 & 0.0296 & 0.206 & -0.0420 & 0.0130 & -0.0116 & 0.131 \\
\hline & & & & $-0.794 * * *$ & -0.149 & -0.113 & $-0.592 * * *$ & -0.0599 & -0.0640 & & 0.0599 \\
\hline \multirow{2}{*}{$\begin{array}{l}\text { Sand, } \\
\mathrm{kg} \mathrm{kg}^{-1}\end{array}$} & & & & 1.00 & -0.0360 & $-0.371^{* * *}$ & $-0.410^{* * *}$ & 0.0719 & -0.0706 & -0.0215 & -0.148 \\
\hline & & & & & 0.0750 & $-0.377 * *$ & $0.609 * * *$ & 0.118 & 0.0704 & & 0.0839 \\
\hline \multirow{2}{*}{$\begin{array}{l}\mathrm{BD}, \\
\mathrm{g} \mathrm{cm}^{-3}\end{array}$} & & & & & 1.00 & $0.264 *$ & $0.270^{*}$ & $-0.574 * * *$ & $0.470 * * *$ & $-0.392 * * *$ & $-0.587 * * *$ \\
\hline & & & & & & $0.353^{* *}$ & $0.418 * * *$ & $-0.682 * * *$ & $0.723 * * *$ & & $-0.424 * * *$ \\
\hline \multirow[t]{2}{*}{ Dexter, $n$} & & & & & & 1.00 & $0.889 * * *$ & -0.0684 & 0.144 & -0.162 & 0.125 \\
\hline & & & & & & & $0.376^{* *}$ & -0.210 & 0.115 & & $-0.370^{* *}$ \\
\hline \multirow[t]{2}{*}{$n^{*}$} & & & & & & & 1.00 & -0.138 & 0.171 & -0.0969 & 0.0406 \\
\hline & & & & & & & & -0.116 & 0.218 & & $-0.245^{*}$ \\
\hline \multirow{2}{*}{$\begin{array}{l}5 \% \text { Arrival } \\
\text { time, } \mathrm{h}\end{array}$} & & & & & & & & 1.00 & $-0.714 * * * 1$ & $0.311^{*}$ & $0.404 * *$ \\
\hline & & & & & & & & & $-0.733^{* * *} *^{1}$ & & $0.276^{*}$ \\
\hline $\begin{array}{l}\text { App. disp., } \\
\text { cm }\end{array}$ & & & & & & & & & 1.00 & -0.181 & $\begin{array}{l}-0.231^{*} \\
-0.119\end{array}$ \\
\hline$\underset{\mathrm{m} \mathrm{d}^{-1}}{\log K_{\mathrm{SAT}}}$ & & & & & & & & & & 1.00 & $0.318^{*}$ \\
\hline$\varepsilon_{-20}, \mathrm{~cm}^{3} \mathrm{~cm}^{-3}$ & & & & & & & & & & & 1.00 \\
\hline
\end{tabular}

$* P<0.05, * * P<0.01$, and $* * * P<0.001$.

$* * *{ }^{1}$, Logarithmic regression. 
$5 \%$ tritium mass arrival time exhibited high tritium recovery rates and high apparent dispersivities (Fig. 5B). Two previous studies based on 733 BTC from a global soil database (Koestel et al., 2012) and on 45 undisturbed topsoil cores from a catchment (Ghafoor et al., 2013) reported similar results. Samples from Silstrup with a longer 5\% tritium mass arrival time were related to areas with lower apparent dispersivities. Ersahin et al. (2002) found the lowest dispersivity to be associated with soil horizons with low macroporosity and a complex structure related to high $B D$ values and narrow pore size distributions. Nine samples from Faardrup deviated from the generally observed tritium recovery, with rates less than $40 \%$ (Fig. 5A). Four of the five samples deviating from the exponential behavior in Fig. 5B exhibited total mass recovery rates less than $40 \%$, which leads to the conclusion that BTC with low mass recovery rates are not reliable predictors of preferential flow and transport processes in structured soils.

\section{Parameter Correlations}

Pearson's correlation coefficients for parameter relationships for the Faardrup and Silstrup samples are listed in Table 2. The analysis for Faardrup is based on a subset of 80 samples (excluding samples with tritium mass recovery rates less than $40 \%$ ) to assure comparability with Silstrup data (65 samples), where tritium mass recovery rates were more than $40 \%$ for all considered samples. The table is split into two parts, with the first part containing physicochemical parameters (OC content, texture, BD, and Dexter $n$ and $\left.n^{*}\right)$ and the second part listing flow and transport parameters (5\% tritium mass arrival time, apparent dispersivity, $\log K_{\mathrm{SAT}}$, and $\left.\varepsilon_{-20}\right)$. The significant correlation coefficients $(r$, marked) were found to be generally higher than 0.34 , with a value of $P<0.001$.
Bulk density was identified as the main driver for several soil functional properties at both sites but, in general, stronger correlations were found for the Silstrup samples. Bulk density was positively correlated with apparent dispersivity but negatively correlated with $5 \%$ mass arrival time and $\log K_{\mathrm{SAT}}$ (Faardrup site only) and $\varepsilon_{-20}$. Texture parameters were not correlated to transport of either air or tritium, but this may be caused by relatively small soil textural variations observed at each field site.

In summary, as BD increases, $5 \%$ mass arrival time decreases and dispersivity increases, indicating more pronounced preferential flow because of faster transport and dispersion of tritium. This was determined for both Faardrup and Silstrup samples but was more pronounced for Silstrup, where the 5\% tritium mass arrival times were significantly shorter (average less than $37 \mathrm{~min}$ compared with $1.8 \mathrm{~h}$ atFaardrup).

Mainly $\varepsilon_{-20}$ but, to some extent, also $\log \left(K_{\mathrm{SAT}}\right)$ were negatively correlated to $\mathrm{BD}$, leading to the conclusion that areas with high BD (more structured) have, in most cases, limited ability to conduct water and air (low $K_{\mathrm{SAT}}$ and low $\varepsilon_{-20}$ values). This seems to be a contradiction because $5 \%$ tritium mass arrival times are shorter in these areas, but this finding is supported by other recent studies (Koestel et al., 2013; Ghafoor et al., 2013; Larsbo et al., 2014). They concluded that high BD values and small macroporosities are presumably associated with reductions of the near- $K_{\mathrm{SAT}}$ and a higher continuity of the macropore network. Thus, for a given irrigation rate, the larger macropores are activated to participate in transport, which shifts from matrix to macropore flow. The magnitude of preferential flow is therefore larger in soils with higher BD (Ghafoor et al., 2013; Larsbo et al., 2014). Another potential reason for such results is the intrinsic experimental variability associated with specific measurements. As
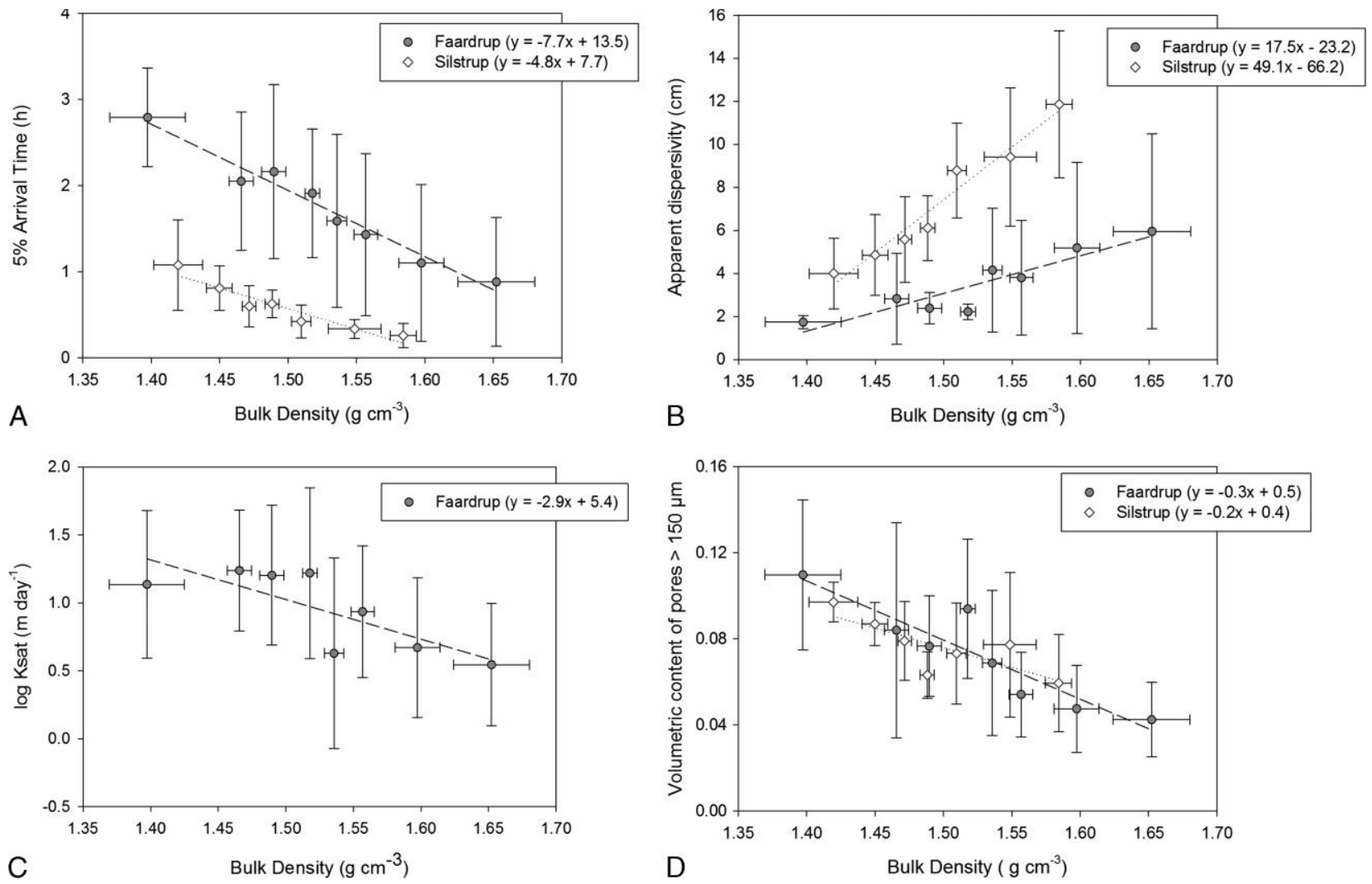

FIG. 6. Five percent tritium mass arrival time (A), apparent dispersivity (B), $\log K_{\mathrm{SAT}}(\mathrm{C})$, and $\varepsilon_{-20}(\mathrm{D})$ for Faardrup and Silstrup, plotted as a function of BD. 
shown in Iversen et al. (2001), a distinct representative elementary sample volume is crucial for consistency of $K_{\mathrm{SAT}}$ measurements. They also demonstrated that $K_{\mathrm{SAT}}$ exhibits higher variability for structured than for homogeneous soils.

\section{The Role of Preferential Flow}

Figure 6 shows correlations between measured flow and transport parameters and BD for Silstrup and Faardrup. The same set of 80 Faardrup samples grouped into eight BD classes and a set of 65 Silstrup samples grouped into seven BD classes were considered for comparison. Panels A and B of Fig. 6 indicate decreasing 5\% tritium mass arrival times and increasing apparent dispersivities with increasing BD for both sites. Silstrup samples showed better correlations with lower S.D. than the Faardrup samples, indicating a higher degree of heterogeneity at the Faardrupsite.

Saturated hydraulic conductivity was only measured on the cores from Faardrup. Measured $K_{\text {SAT }}$ values varied significantly across this field (Fig. 6C) and were negatively correlated to BD, although not as strong as expected. Figure 6D shows a decrease in the macroporosity, $\varepsilon_{-20}$, with increasing $\mathrm{BD}$, being slightly more significant and scattered for Faardrup than Silstrup. This behavior is probably caused by the higher heterogeneity of BD at the Faardrup site, indicating that there is less space for air transmission in more compacted soils. Panels C and D of Fig. 6 reinforce the findings of Loll et al. (1999), indicating that both air and water transport follow the same trend with regard to BD despite the high variance of both parameters. The relationship between BD and volumetric macropore content was nearly identical for both sites, whereas the relationships between 5\% tritium mass arrival time and apparent dispersivity with BD were markedly different, despite similar trends.

Ersahin et al. (2002) concluded that high macroporosity resulted in high pore water velocities, particularly in the A and $\mathrm{B}_{\mathrm{W}}$ horizons, generally matching high dispersion coefficients. However, they also found extensive mass exchange between macropores and the soil matrix for the same soils, as evidenced by pronounced tailing of the measured BTC. It was further shown that, as the BD decreases with increasing $\varepsilon_{-20}$, the presence of airfilled pores leads to a reduction of the preferential flow potential. Interestingly, the increase in macroporosity was slightly more evident for Faardrup, as the BD decreased $(r=-0.59$ for Faardrup and $r=-0.42$ for Silstrup). Results presented in Fig. 6 and Table 2 lead to the conclusion that preferential flow was more pronounced at the Silstrup site, leading to higher susceptibility to leaching of agrochemicals and colloids (Norgaard et al., 2012). As demonstrated in numerous studies (e.g., Petersen et al., 1997; Gjettermann et al., 2009; Ersahin et al., 2002), pore geometry and macropore features are highly affected by soil management. Presumably, the period without tillage (almost 2 years) at Silstrup
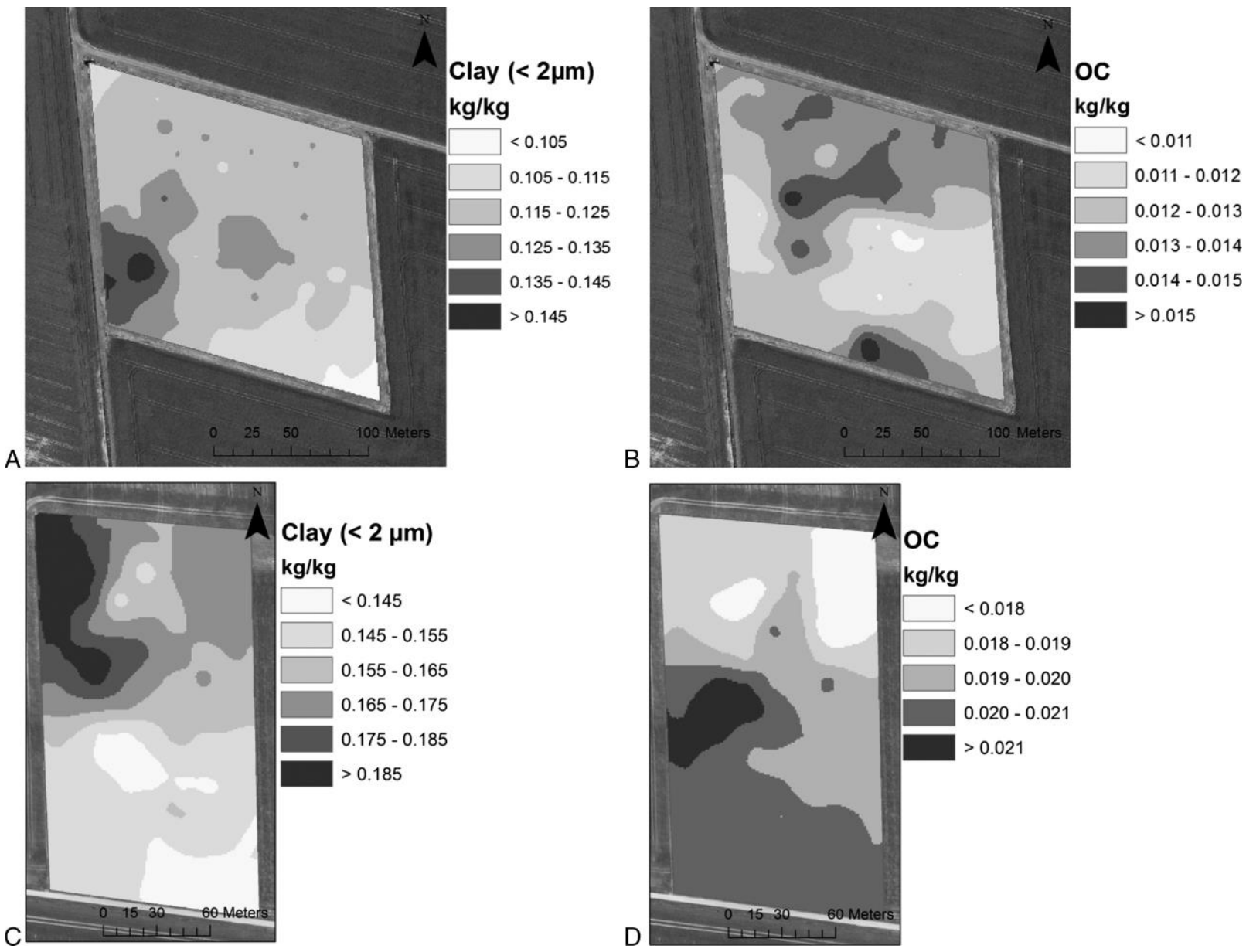

FIG. 7. Contour maps for $C L$ and $O C$ contents for the Faardrup $(A, B)$ and Silstrup (C, D) fields. 
may have contributed to the formation of a well-developed network of biopores.

To further analyze the potential for preferential flow and transport, the effects of CL and OC contents were considered. Contour maps showing the spatial variation of CL and OC contents are shown in panels A and B (Faardrup), and C and D (Silstrup) of Fig. 7. Panels A to D of Fig. 8 depict contour plots for $\mathrm{BD}, 5 \%$ tritium mass arrival time, apparent dispersivity, and $K_{\mathrm{SAT}}$ for Faardrup. The sandy loam soil in Faardrup exhibited regions with relatively high $\mathrm{BD}\left(>1.53 \mathrm{~g} \mathrm{~cm}^{-3}\right)$ and significant fracturing, which is common for soils composed of glacial deposits overlying clayey till. From the same regions, we found the short 5\% tritium mass arrival times. This also suggests that the sample-scale network continuity in such preferential flow regions is higher than in more homogeneous matrix regions.

In Faardrup, the highest CL contents $\left(>0.125 \mathrm{~kg} \mathrm{~kg}^{-1}\right)$ were found in the southwest corner of the field, whereas the OC content was highest in the north and south central areas. The highest preferential flow potential was found in several areas, partly where CL contents were elevated (small area in the southwestern part of the field), with Dexter $n$ values greater than 10 and $n^{*}$ values greater than 20 . This resulted in a "preferential flow belt" stretching from the southwestern to the northeastern part of the field and contradicts the correlation matrix data between CL and 5\% tritium mass arrival times (Table 2) in a small area within the southwestern part of the field. These areas in the belt are low-OC regions where the soil is more compact and has a higher BD (Fig. 8A), resulting in short 5\% tritium mass arrival times (Fig. 8B), high apparent dispersivities (Fig. 8C), and high tritium recovery rates. The 5\% tritium mass arrival time ranged from $11 \mathrm{~min}$ to $4.6 \mathrm{~h}$ (average, $1.8 \mathrm{~h}$ ), tritium recoveries ranged from $11 \%$ to $95 \%$ (average, $59 \%$ ), and apparent dispersivity ranged from 1.1 to $14 \mathrm{~cm}$ (average, $3.6 \mathrm{~cm}$ ). A single spot in the southeast, with BD more than $1.53 \mathrm{~g} \mathrm{~cm}^{-3}$ and high 5\% tritium mass arrival times, did not follow this general trend. Jarvis et al. (2007) found that agricultural top soils with fine textures and/or low OM contents are also characterized by low lateral mass exchange rates and are therefore prone to elevated macropore flow.

Figure 8D shows substantial variations of $K_{\mathrm{SAT}}$ across the field in Faardrup, with values ranging from less than 1 to more than $35 \mathrm{~m} \mathrm{~d}^{-1}$. The areas with high $K_{\text {SAT }}$ values were located in the northern part of the field, which also exhibited high OC contents, presumably because of an increase of interactions between water and soil-matrix in high $\mathrm{OC}$ areas.

Panels A and C of Fig. 9 depict contour plots of BD, 5\% tritium mass arrival time, and apparent dispersivity for the Silstrup site. Norgaard et al. (2012) found higher BD in the northern part of the field, correlating well with the higher CL content and higher Dexter $n$ but also in the very southern areas where the OC content was higher. This accentuates the fact that, despite both
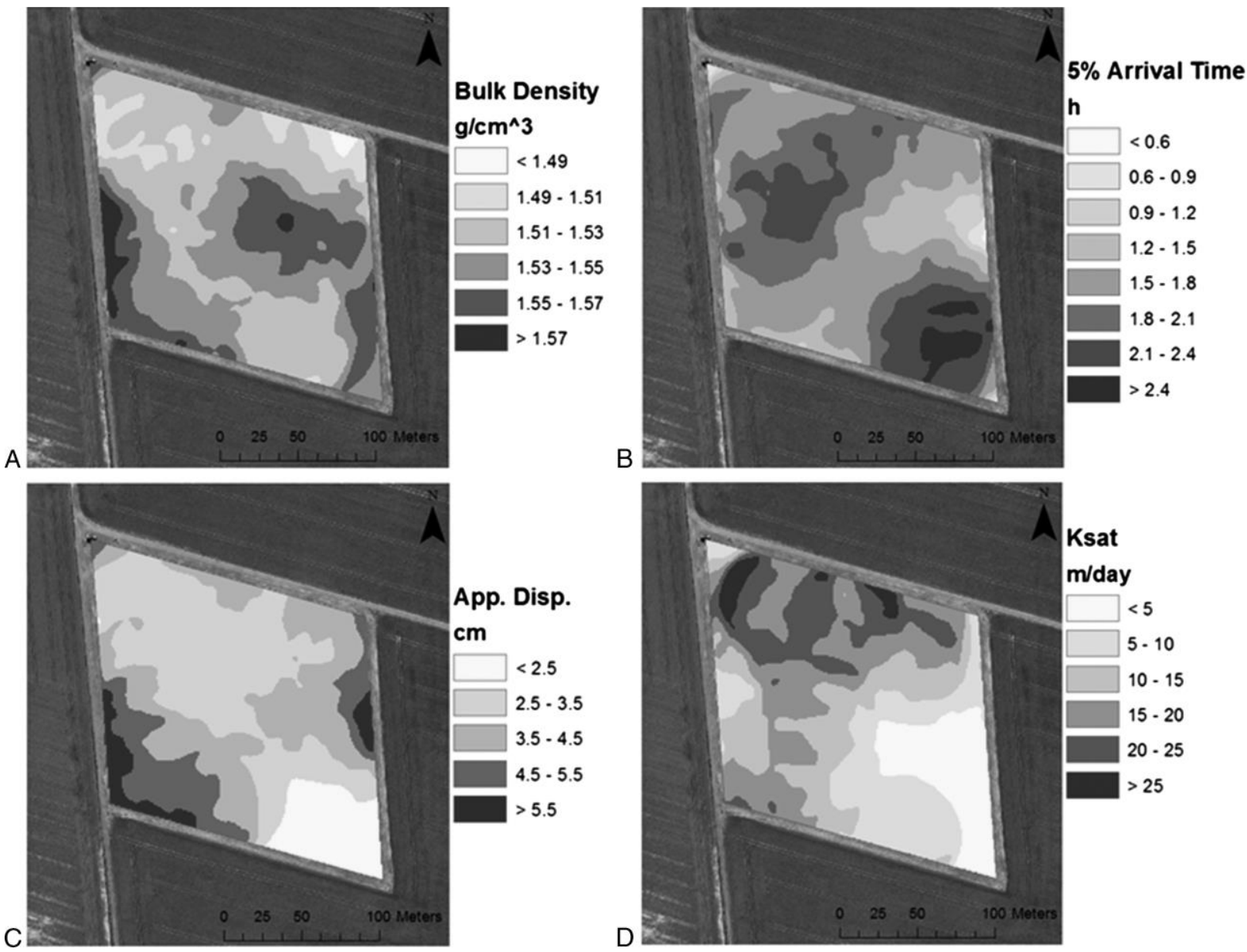

FIG. 8. Contour maps for BD (A), $5 \%$ tritium mass arrival time (B), apparent dispersivity (C), and $K_{\mathrm{SAT}}(\mathrm{D})$ for the Faardrup field site. 

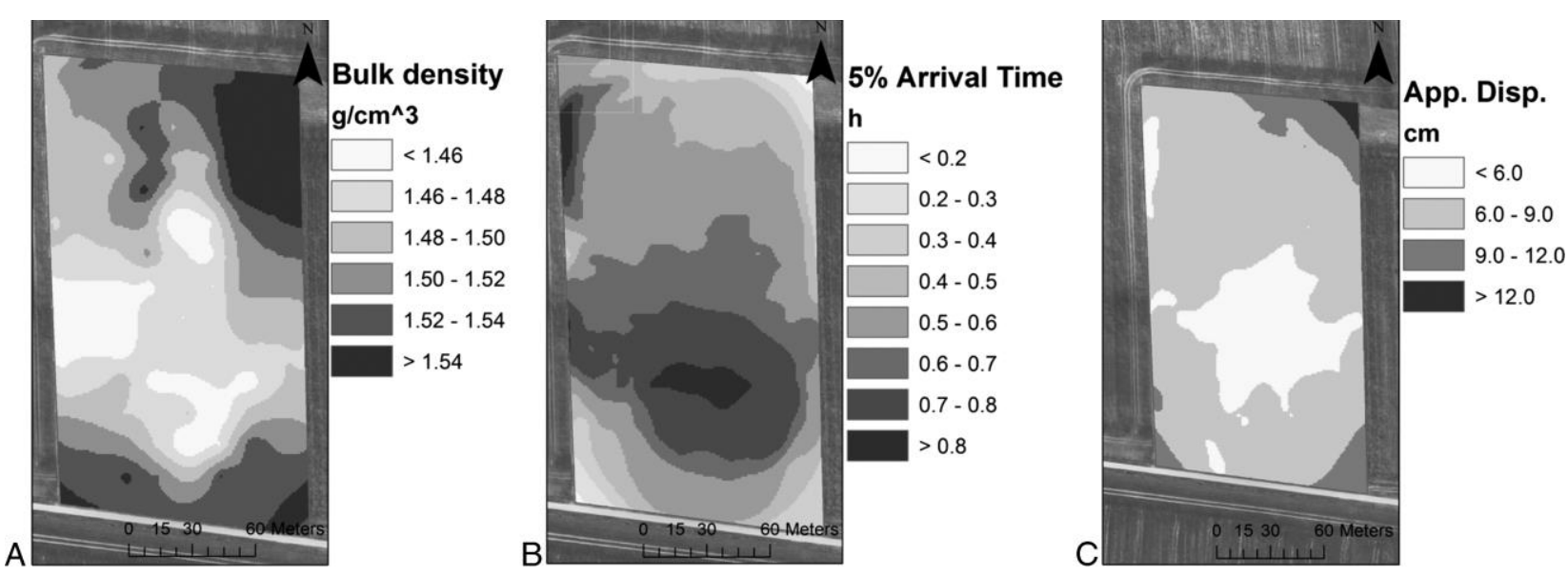

FIG. 9. Contour maps for BD (A), 5\% tritium mass arrival time (B), and apparent dispersivity (C) for the Silstrup field site.

fields being classified as sandy loams, their soil structures differ mainly because of a greater homogeneity in the soil basic properties at Silstrup. The cores from Faardrup followed the same tendency, with low $5 \%$ tritium mass arrival times and high apparent dispersivities related to high $\mathrm{BD}$ regions.

A well-developed soil structure (higher BD partly related to higher CL contents), with a few well-aligned, less tortuous, and well-connected macropores resulted in more pronounced preferential flow at Silstrup compared with the less structurally developed soil at Faardrup (e.g., Anderson and Bouma, 1977; Norgaard et al., 2012; Jarvis et al., 2012; Larsbo et al., 2014). On the other hand, lateral mass exchange was more pronounced at the Faardrup site, as evidenced by the more symmetrical shape of the majority of the BTC.

\section{SUMMARY AND CONCLUSIONS}

This study was focused on assessing effects of soil compaction, OC content, and texture on macroporosity and potential for preferential flow and transport of water and tritium at two Danish field sites.

Although both sites exhibited loamy soil textures, one site had significantly higher OC and fines contents. Bulk density was found to be the major parameter affecting preferential flow and transport at the Faardrup and Silstrup sites. It was highly correlated with all transport parameters that were derived from the tritium breakthrough experiments. At the Faardrup site, areas with high BD, in general, coincided with the areas with low OC contents. Samples from these locations were associated with short $5 \%$ tritium mass arrival times, indicating a high potential for preferential flow and transport. The remaining field was predominantly governed by matrix flow and transport.

Interestingly, the relationships between $\mathrm{BD}$ and tritium transport parameters were markedly different for the two sites, despite almost identical correlations between BD and $\varepsilon_{-20}$. This suggests that differences in the macropore network caused by differences in the contents of OC and fines (presence of better connected and less tortuous macropores at Silstrup as evidenced by the breakthrough behavior) yielded higher preferential transport at Silstrup. The decline of both $\varepsilon_{-20}$ and $K_{\text {SAT }}$ with increasing BD, which at the same time seems to increase preferential flow potential, further implies the importance of the macropore network (e.g., local and sample-scale continuity) along with the fines and OC contents for water, air, and solute transport.

These results highlight the importance of further studies relating soil structure, compaction, texture, and chemical transport, in particular, for complex and heterogeneous fields such as in Faardrup and Silstrup.

\section{REFERENCES}

Anamosa P.R., P.Nkedi-kizza, W.G. Blue, and J. B. Sartain. 1990. Water movement through an aggregated, gravelly oxisol from Cameroon. Geoderma. 46:263-281.

Anderson J. L., and J. Bouma. 1977. Water movement through pedal soils: I. Saturated flow. Soil Sci. Soc. Am. J. 41:413-418.

Angulo-Jaramillo R., J. P. Gaudet, J. L. Thony, and M. Vauclin. 1996. Measurement of hydraulic properties and mobile water content of a field soil. Soil Sci. Soc. Am. J. 60:710-715.

Beven K., and P.Germann. 2013. Macropores and water flow in soils revisited. Water Resour. Res. 49:3071-3092.

Biggar J. W., and D. R. Nielsen. 1962. Miscible displacement in soils: II. Behavior of tracers. Soil Sci. Soc. Am. J. 26:125-128.

Camobreco V. J., B. K. Richards, T. S. Steenhuis, J. H. Peverly, and M. B. McBride. 1996. Movement of heavy metals through undisturbed and homogenized soil columns. Soil Sci. 161:740-750.

de Jonge L. W., P. Moldrup, and P. Schjønning. 2009. Soil Infrastructure, Interfaces and Translocation Processes in Inner Space ("Soil-It-Is"): Towards a road map for the constraints and crossroads of soil architecture and biophysical processes. Hydrol. Earth Syst. Sci. 13:1485-1502.

Dennis J. E., D. M. Gay, and R. E. Walsh. 1981. An adaptive nonlinear leastsquares algorithm. ACM T. Math. Software 7:348-368.

Dexter A. R. 1988. Advances in characterization of soil structure. Soil Till. Res. 11:199-238.

Dexter A. R., G. Richard, D. Arrouay, E. A. Czyz, C. Jolivet, and O. Duval. 2008. Complexed organic matter controls soil physical properties. Geoderma. 144:620-627.

Ersahin S., R. I. Papendick, J. L. Smith, C. K. Keller, and V.S. Manoranjan. 2002. Macropore transport of bromide as influenced by soil structure differences. Geoderma. 108:207-223.

Flury M., H. Flühler, H. W. A. Jury, and J. Leuenberger. 1994. Susceptibility of soils to preferential flow of water. Water Resour. Res. 30:1945-1954.

Gaber H. M., W.P.Inskeep, S. D. Comfort, and J. M. Wraith. 1995. Nonequilibrium transport of atrazine through large intact soil cores. Soil Sci. Soc. Am. J. 59:60-67.

Gee G.W., and D. Or. 2002. Methods of Soil Analysis, Part 4. Physical Methods. Book Series No. 5. Soil Science Society of America, Madison, WI.

Ghafoor A., M. Larsbo, J. Koestel, J. Moeys, and N. Jarvis. 2013. Soil properties and susceptibility to preferential solute transport in tilled topsoil at the catchment scale. J. Hydrol. 492:190-199. 
Gjettermann B., C. T. Petersen, C. B. Koch, N. H. Spliid, C. Grøn, D. L. Baun, and M. Styczen. 2009. Particle-facilitated pesticide leaching from different structured soil monoliths. J. Environ. Qual. 38:2382-2393.

Horn R., H. Taubner, M. Wuttke, and T. Baumgartl. 1994. Soil physical properties related to soil structure. Soil Till. Res. 30:187-216.

Iversen B. V.,P. Moldrup, P. Schjønning, and P.Loll. 2001. Air and water permeability in differently textured soils at two measurement scales. Soil Sci. 166:643-659.

Iversen B. V., M. Lamandé, S. B. Torp, M. H. Greve, G. Heckrath, L. W. de Jonge, P. Moldrup, and O. H. Jacobsen. 2012. Macropores and macropore transport: Relating basic soil properties to macropore density and soil hydraulic properties. Soil Sci. 177:535-542.

Jarvis N., M. Larsbo, S. Roulier, A. Lindahl, and L. Persson. 2007. The role of soil properties in regulating non-equilibrium macropore flow and solute transport in agricultural topsoils. Eur. J. Soil Sci. 58:282-292.

Jarvis N. J. 2007. A review of non-equilibrium water flow and solute transport in soil macropores: Principles, controlling factors and consequences for water quality. Eur. J. Soil Sci. 58:423-546.

Jarvis N. J., J. Moeys, J. Koestel, and J. M. Hollis. 2012. Preferential flow in a pedological perspective. In: Hydropedology: Synergistic Integration of Soil Science and Hydrology. Lin H. (ed.). Waltham, MA, Academic Press, pp. 75-120.

Jarvis N. J., J. K. Koestel, I. Messing, J. Moeys, and A. Lindahl. 2013. Influence of soil, land use and climatic factors on the hydraulic conductivity of soil. Hydrol. Earth Syst. Sc. 17:5185-5195.

Jury W.A., and K. Roth. 1990. Transfer functions and solute movement through soil: Theory and applications. Birkhäuser Verlag, Basel, Switzerland.

Kjaer J., P.Olsen, K. Bach, H. C. Barlebo, F. Ingerslev, M. Hansen, and B.H. Sorensen. 2007. Leaching of estrogenic hormones from manure-treated structured soils. Environ. Sci. Technol. 41:3911-3917.

Kjaer J., A. E. Rosenbom, W. Brusch, R. K. Juhler, L. Gudmundsson, F. Plauborg, R. Grant, and P.Olsen. 2011. The Danish Pesticide Leaching Assessment Programme: Monitoring results May 1999-June 2010. Geological Survey of Denmark and Greenland, Copenhagen, Denmark.

Kjaergaard C., T. G. Poulsen, P. Moldrup, and L. W. de Jonge. 2004. Colloid mobilization and transport in undisturbed soil columns. I. Pore structure characterization and tritium transport. Vadose Zone J. 3:413-423.

Klute A, and C. Dirksen. 1986. Hydraulic conductivity and diffusivity, laboratory methods. In: Methods of Soil Analysis. Part I. Klute A. (ed.). SSSA, Madison, WI, pp. 687-732.

Koestel J. K., J. Moeys, and N. J. Jarvis. 2011. Evaluation of nonparametric shape measures for solute breakthrough curves. Vadose Zone J. 10:1261-1275.

Koestel J. K., J. Moeys, and N. J. Jarvis. 2012. Meta-analysis of the effects of soil properties, site factors and experimental conditions on preferential solute transport. Hydrol. Earth Syst. Sc. 16:1647-1665.
Koestel J. K., T. Norgaard, N. M. Luong, A. L. Vendelboe, P. Moldrup, N. J. Jarvis, M. Lamandé, B. V.Iversen, and L. W. de Jonge. 2013. Links between soil properties and steady-state solute transport through cultivated topsoil at the field scale. Water Resour. Res. 49:1-19.

Langner H. W., H. M. Gaber, J. M. Wraith, B. Huwe, and W.P.Inskeep. 1999. Preferential flow through intact soil cores: Effects of matric head. Soil Sci. Soc. Am. J.63:1591-1598.

Larsbo M., J. Koestel, and N. Jarvis. 2014. Controls of macropore network characteristics on preferential solute transport. Hydrol. Earth Syst. Sci. Discuss. 11:9551-9588.

Lin H. S., K. J. McInnes, L. P. Wilding, and C. T. Hallmark. 1999. Effects of soil morphology on hydraulic properties: I. Quantification of soil morphology. Soil Sci. Soc. Am. J. 63:948-954.

Lindhardt B., C. Abildrup, H. Vosgerau, P. Olsen, S. Torp, B. V.Iversen, J. O. Jorgensen, F. Plauborg, P.Rasmussen, and P.Gravesen. 2001. The Danish Pesticide Leaching Assessment Programme: Site Characterization and Monitoring Design. Copenhagen, Geological Survey of Denmark and Greenland.

Loll P., P. Moldrup, P. Schjønning, and H. Riley. 1999. Predicting saturated hydraulic conductivity from air permeability: Application in stochastic water infiltration modeling. Water Resour. Res. 35:2387-2400.

Norgaard T., P. Moldrup, A. Olsen, A. Vendelboe, B. V.Iversen, M. H. Greve, J. Kjaer, and L. W. de Jonge. 2012. Comparative mapping of soil physicalchemical parameters and structural parameters at field scale to identify zones of enhanced leaching risk. J. Environ. Qual. 42:271-283.

Oades J. M. 1993. The role of biology in the formation, stabilization and degradation of soil structure. Geoderma. 56:377-400.

Petersen C. T., S. Hansen, and H. E. Jensen. 1997. Tillage induced horizontal periodicity of preferential flow in the root zone. Soil Sci. Soc. Am. J. 61:586-594.

Schjønning P., L. W. de Jonge, L. J. Munkholm, , B. T. Christensen, and J. E. Olesen. 2012. Clay dispersibility and soil friability-Testing the soil clay-to-carbon saturation concept. Vadose Zone J. 11:174-187.

Seyfried M. S., and P.S. C. Rao. 1987. Solute transport in undisturbed columns of an aggregated tropical soil: Preferential flow effects. Soil Sci. Soc. Am. J. 51:1434-1444.

Soil Survey Staff. 1999. Soil Taxonomy. A Basic System of Soil Classification for Making and Interpreting Soil Surveys. 2nd Ed. Natural Resources Conservation Service, USDA, Washington, DC.

Stagnitti F., G. Allinson, M. Morita, M. Nishikawa, H. Il, and T. Hirata. 2000 Temporal moments analysis of preferential solute transport in soils. Environ. Model. Assess. 5:229-236.

Vervoort R. W., D. E. Radcliffe, and L. T. West. 1999. Soil structural development and preferential solute flow. Water Resour. Res. 35:913-928. 